\title{
Antimicrobial Activity of Duck Egg Lysozyme against Salmonella enteritidis
}

\author{
Naknukool, S., Hayakawa, S., Uno, T., Ogawa, M. \\ Department of Biochemistry and Food Science, Faculty of Agriculture, Kagawa University, \\ Ikenobe, Miki, Kagawa, Japan 761-0795 \\ hayakawa@ag.kagawa-u.ac.jp
}

\begin{abstract}
The objective of the study was to investigate antimicrobial activity of native and reduced forms of duck lysozyme (dLz) against Salmonella enteritidis. Moreover, antimicrobial activity of $\mathrm{dLz}$ was compared with chicken lysozyme (cLz). The purified dLz was reduced with dithiothreitol. Free $\mathrm{SH}$ groups of reduced dLz were trapped with iodoacetamide. Lytic activity against Micrococcus luteus of reduced dLz decreased according to a period of reduction time. Whereas, reduction of $\mathrm{dLz}$ enhanced antimicrobial activity against $S$. enteritidis IFO3313 and other S. enteritidis found in contaminated food. The antimicrobial activity of reduced $\mathrm{dLz}$ depended on the time of reduction as $1.5 \mathrm{~h}$ reduction showed highest antimicrobial activity. Incubation of lysozyme with $S$. enteritidis at various temperatures showed that the optimum temperature for antimicrobial activity of reduced $\mathrm{Lz}$ is $45-49{ }^{\circ} \mathrm{C}$. The presence of polyphosphate $(0.05-0.10 \%)$ enhanced the antimicrobial effect of reduced dLz. On the other hand, addition of $\mathrm{NaCl}(0.05-0.10 \mathrm{M})$, glucose $(10 \%)$, sucrose $(10 \%)$ and bovine serum albumin $(0.5-1.0 \%)$ decreased the antimicrobial activity of reduced dLz. Meanwhile, glycine (0-0.5\%) did not show any effect on reduced dLz inhibitory activity. Combination of lactoferrin $(0.1 \mathrm{mg} / \mathrm{ml})$ and reduced $\mathrm{dLz}(0.1 \mathrm{mg} / \mathrm{ml})$ showed a synergistic effect. In all conditions, $\mathrm{dLz}$ showed higher activity than $\mathrm{cLz}$ in both native and reduced forms. The result of the study indicated that reduced $\mathrm{dLz}$ trends to be a more efficient antimicrobial agent against $S$. enteritidis. To achieve the highest sufficiency, the essential roles of food components and incubation temperature should be concerned in reduced $\mathrm{dLz}$ application.
\end{abstract}

Keywords: Duck lysozyme, Antimicrobial activity, Reduced lysozyme

\section{Introduction}

A trend in non-chemical food preservation is alerted according to the demand of consumers who are concerned about health caring. Natural food antimicrobial agents such as lysozyme, nisin, lactoferrin and lactoperoxidase are widely used in the food industry to inhibit growth of microorganism including foodborne pathogens. Lysozyme (Lz) has been known as a basic protein in egg white, containing muramidase activity. It specifically hydrolyses the 1,4- $\beta$-linkages between $\mathrm{N}$-acetyl muramic acid and $\mathrm{N}$-acetylglucosamine in the glycan, which stabilizes cell walls of gram-positive bacteria. According to this effect, Lz strongly affects gram-positive bacteria but not much to gram-negative bacteria because of the composition of outer membrane. Many researchers attempt to enhance the antimicrobial activity of Lz against 
gram-negative bacteria by using chemical or physical treatment to disrupt the bacteria membrane (Vannini et al., 2004), combining with other antimicrobial or/and chemical substances (Facon, 1996; Boland et al., 2003; Branen et al., 2004) and modifying the structure of Lz (Ibrahim et al., 1992; Liu et al., 2000; Mine et al., 2004; Hunter et al., 2005). Recently, reduction of Lz's disulfide bonds, exposing the hydrophobic surface of Lz, was introduced to improve the antimicrobial action of Lz against S. enteritidis (Touch et al., 2004)

Most of the reports on antimicrobial activity are about chicken Lz (cLz). Duck Lz (dLz) shows some differences in amino acid sequence. The molecule of $\mathrm{dLz}$ is stabilized with four disulfide bonds in the same position as cLz. dLz reveals enzymatic activity 1.34-1.53 time that of chicken Lz (cLZ). It contains 3 isoforms (DL-1, DL-2 and DL-3) which are different according to the displacement of Ser-37 to Gly, Gly-71 to Arg (DL-2 and DL-3) and Pro-79 to Arg (DL-3). The last two displacements induce the conformational change of dLz from $\beta$-turn to random coil (Prager et al., 1971; Hermann et al., 1973; Kondo et al., 1982).

In the present paper, we investigated the antimicrobial activity of $\mathrm{dLz}$ against $S$. enteritidis to create an alternative agent for food preservation. Furthermore, dLz was studied in various conditions for understanding in the effect of food components on antimicrobial activity of dLz.

\section{Materials and Methods}

Duck eggs were purchase from Agricultural, Food and Environmental Sciences Research Centre of Osaka Prefecture (Osaka, Japan). Hen egg white lysozyme, crystallized six times, and Micrococcus luteus cell were supplied by Seikagaku Kogyo Co. Ltd. (Tokyo, Japan). SP-Sepharose ${ }^{\mathrm{TM}}$ Fast Flow, used for dLz purification, was purchased from Amersham Bioscience (New Jersey, USA). Dithiolthreiol (DTT) and iodoacetamide (IAM) were obtained from Nacalai Tesque Inc. (Kyoto, Japan). Unless specified, all other chemicals used were reagent grade.

\section{Duck lysozyme purification}

Duck egg white was mixed gently with 3-fold volumes of sodium acetate buffer (ionic strength $0.05, \mathrm{pH} 5.0$ ). After centrifuged at $6000 \times g$ for $15 \mathrm{~min}$, the supernatant was applied to SP-Sepharose column and washed with sodium acetate buffer before eluted stepwise with $0.1,0.3$ and $0.5 \mathrm{M} \mathrm{NaCl}$ in sodium phosphate buffer (ionic strength $0.05, \mathrm{pH}$ 9.0). The dLz containing fractions were collected and dialysed against Mili $Q$ water for 3 days before freeze-drying for further experiment. The purity of $\mathrm{dLz}$ containing fractions was determined by SDS-PAGE in a 15\% gel (Laemmli, 1970).

\section{Reduction of Lysozyme}

The $1 \mathrm{mg} / \mathrm{ml} \mathrm{Lz}$ in $10 \mathrm{mM}$ Tris-HCl buffer, $\mathrm{pH} 8.0$ were reduced by $2 \mathrm{mM}$ DTT at $30{ }^{\circ} \mathrm{C}$ for $0.5-4 \mathrm{~h}$ and treated with $5 \mathrm{mM}$ IAM at $30{ }^{\circ} \mathrm{C}$ for $1 \mathrm{~h}$ in the dark. Reduced Lz were dialysed against Mili $\mathrm{Q}$ water for 3 days to remove salts and excess reagents before freeze-drying for further use. 


\section{Lytic Activity Assay}

Lytic activity of Micrococcus luteus was determined according to turbidometic method. Dried cells of $M$. luteus were suspended in $55 \mathrm{mM}$ sodium phosphate buffer, $\mathrm{pH} 6.2$ to the concentration of $0.4 \mathrm{mg} / \mathrm{ml}$ and stirred at $4{ }^{\circ} \mathrm{C}$ overnight. The decrease of absorbance at $700 \mathrm{~nm}, 37{ }^{\circ} \mathrm{C}$ was reported after the addition of bacteria suspension $2.88 \mathrm{ml}$ and $0.12 \mathrm{ml}$ of each reduce/non-reduced dLz solution $(1 \mathrm{mg} / \mathrm{ml})$ for $2 \mathrm{~min}$. One unit of lytic activity is the amount of $\mathrm{Lz}$ that produce 0.001 decrease in absorbance per min. The activity is expressed in $\mathrm{U} / \mathrm{mg}$ of protein.

\section{Determination of Antimicrobial Activity}

The bacteria that were used in this study were $S$. enteritidis IFO3313, obtained from NITE Biological Resource Centre (Chiba, Japan) and other strains from contaminated food, E991011, E990241, E990925, E990253 and E990579, obtained from National Institute of Infectious Diseases (Tokyo, Japan). They were cultured overnight at $37{ }^{\circ} \mathrm{C}$ in a medium containing $1 \%$ polypeptone, $0.5 \%$ yeast extract, $0.3 \%$ glucose, $1 \% \mathrm{NaCl}, 0.1 \% \mathrm{MgSO}_{4}-7 \mathrm{H}_{2} \mathrm{O}$, and $1.5 \%$ agar at $\mathrm{pH} 7.0$. The cells were resuspended in $10 \mathrm{mM}$ phosphate buffer $\mathrm{pH} 7.2$, containing $0.15 \mathrm{mM} \mathrm{NaCl}$ before diluted with the same buffer to achieve the concentration of $10^{5} \mathrm{CFU} / \mathrm{ml}$ as measured by the absorbance at $600 \mathrm{~nm}$.

$10^{5} \mathrm{CFU} / \mathrm{ml}$ bacteria solution was incubated with reduced/non-reduced $\mathrm{Lz}$ at the final concentration of $0.1 \mathrm{mg} / \mathrm{ml}$ in $10 \mathrm{mM}$ phosphate buffer, $\mathrm{pH} 7.2$ at $30{ }^{\circ} \mathrm{C}$ for $1 \mathrm{~h}$. Countable dilution of bacteria solution, diluted with saline water $(0.15 \mathrm{mM} \mathrm{NaCl}), 100 \mu$ l was streaked onto desoxycholate-hydrogen sulfide lactose agar (DHL) and incubated at $37{ }^{\circ} \mathrm{C}$ for $24 \mathrm{~h}$ before examined for characteristic colonies. Controls were subject to the same treatment by using water instead of the protein solutions. The antimicrobial activity was expressed as $\log$ $\mathrm{A}_{0} / \mathrm{A}_{1} \quad\left(\mathrm{~A}_{0}=\mathrm{CFU} / \mathrm{ml}\right.$ of control; $\mathrm{A}_{1}=\mathrm{CFU} / \mathrm{ml}$ of sample $)$. The experiment was done in triplicate.

\section{The Effect of Incubation Temperature}

$0.1 \mathrm{mg} / \mathrm{ml}$ of reduced Lz was incubated with $10^{5} \mathrm{CFU} / \mathrm{ml}$ S. enteritidis IFO 3313 at various incubation temperatures $\left(30,45,47\right.$, and $\left.49{ }^{\circ} \mathrm{C}\right)$ for $1 \mathrm{~h}$. Then the antimicrobial activity of reduced $\mathrm{Lz}$ was determined as mentioned above.

The Effect of Food Component and Combination with Lactoferrin to Antimicrobial Activity of Duck and Chicken Lysozyme

The combination effects of $0.1 \mathrm{mg} / \mathrm{ml}$ reduced $\mathrm{Lz}$ with different kinds of food components were investigated. The food components used in this study are as follows: 0.05 and $0.1 \mathrm{M} \mathrm{NaCl}, 5$ and 10\% Glucose (Glu), 5 and 10\% Sucrose (Suc), 0.1 and $0.5 \%$ Glycine (Gly), 0.5 and 1.0\% BSA, 0.05 and $0.10 \%$ polyphosphate and $0.1 \mathrm{mg} / \mathrm{ml}$ lactoferrin. The mixtures of Lz and food components were incubated with $10^{5} \mathrm{CFU} / \mathrm{ml}$ S. enteritidis IFO 3313 at $30{ }^{\circ} \mathrm{C}$, for $1 \mathrm{~h}$ before determined the antimicrobial activity as described above. The effect of $0.50 \%$ glycine, $0.10 \%$ polyphosphate and $0.2 \mathrm{mg} / \mathrm{ml}$ lactoferrin were also studied by incubated in the same condition above. 


\section{Result and Discussion}

The dLz was obtained by single-step purification, using ion exchange chromatography. After eluted with sodium phosphate buffer (ionic strength $0.05, \mathrm{pH} 9$ ), containing 0.1, 0.3 and $0.5 \mathrm{M} \mathrm{NaCl}$, the result was as shown in Fig. 1. Peak 3 (P3) and Peak 4 (P4) presented on the same position $(\sim 14 \mathrm{kDa})$ on SDS-PAGE that related to the molecular mass of Lz. To identify these two bands, the N-terminal amino acid sequence was analysed and resulted in four amino acid sequences (KVYS) that completely same as reported. Thus, these two bands were confirmed as dLz. The difference of these two peaks may be due to the multiple forms of $\mathrm{dLz}$ that have been mentioned in previous works (Prager et al., 1971; Hermann et al., 1973; Kondo et al., 1982).
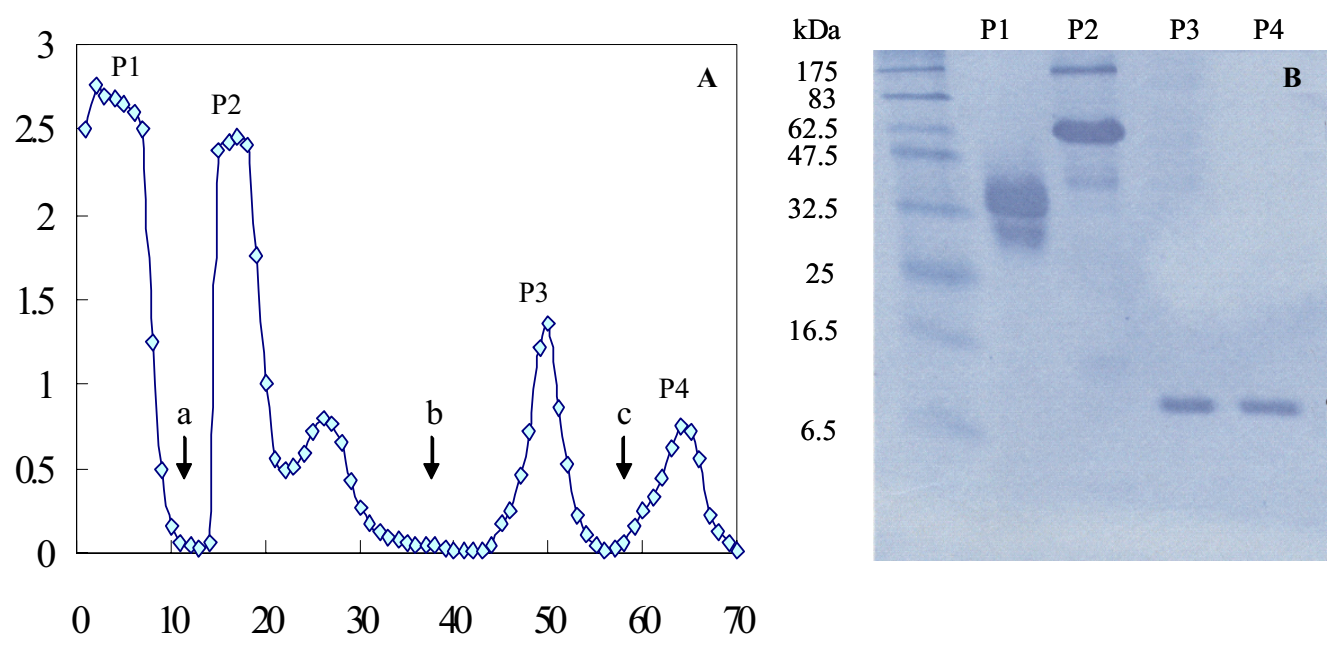

Figure 1. Chromatogram (A) and SDS-PAGE pattern (B) of duck lysozyme from SP-Sepharose column eluted with sodium carbonate buffer (ionic strength 0.05, $\mathrm{pH} 9.0$ ), containing 0.1 (a), 0.3 (b) and 0.5 (c) $\mathrm{M} \mathrm{NaCl}$.

After being reduced by $2 \mathrm{mM}$ DTT and trapped free sulfhydryl group with IAM, the lytic activity of dLz against M. luteus decreased as a function of reduction time (Fig. 2A). The reduction of $\mathrm{SH}$ groups results in the disruption of the conformation forming the active site, due to unfolding of its molecule which affect muramidase activity of Lz (Gilquin et al., 2000). On the other hand, the antimicrobial activity of dLz against $S$. enteritidis IFO3313 increased depending on reduction time (Fig. 2B). The reduction time of $1.5 \mathrm{~h}$ showed the highest antimicrobial activity against $S$. enteritidis IFO3313. In cLz, the exposure of hydrophobic region which is buried in the interior of the compact lysozyme molecule was reported after it was reduced by DTT (Touch et al., 2004). Increasing in exposed hydrophobic region is an important factor of binding affinity which can expand the spectrum of $\mathrm{Lz}$ antimicrobial activity against gram-negative bacteria, containing of the lipopolysaccharide at the outer membrane. In the reduction time over $1.5 \mathrm{~h}$, the antimicrobial activity enhancement of the reduced $\mathrm{Lz}$ was slightly decreased. These may result from the protein-protein interaction, occurring via the hydrophobic association. The reduction time of $1.5 \mathrm{~h}$ was selected to be the condition of reduced $\mathrm{Lz}$ in following experiments. 
In comparison of the antimicrobial activity of native and reduced Lz (Fig. 3), reduced Lz of both species demonstrated stronger antimicrobial activity against $S$. enteritidis IFO3313 than native counterpart. The efficiency of reduced Lz against $S$. enteritidis from contaminated food was also investigated (Fig. 4). The result presented that reduced Lz showed wide antimicrobial efficiency against food-contaminating Salmonella. Moreover, reduced dLz possessed higher antimicrobial action against all $S$. enteritidis than cLz.
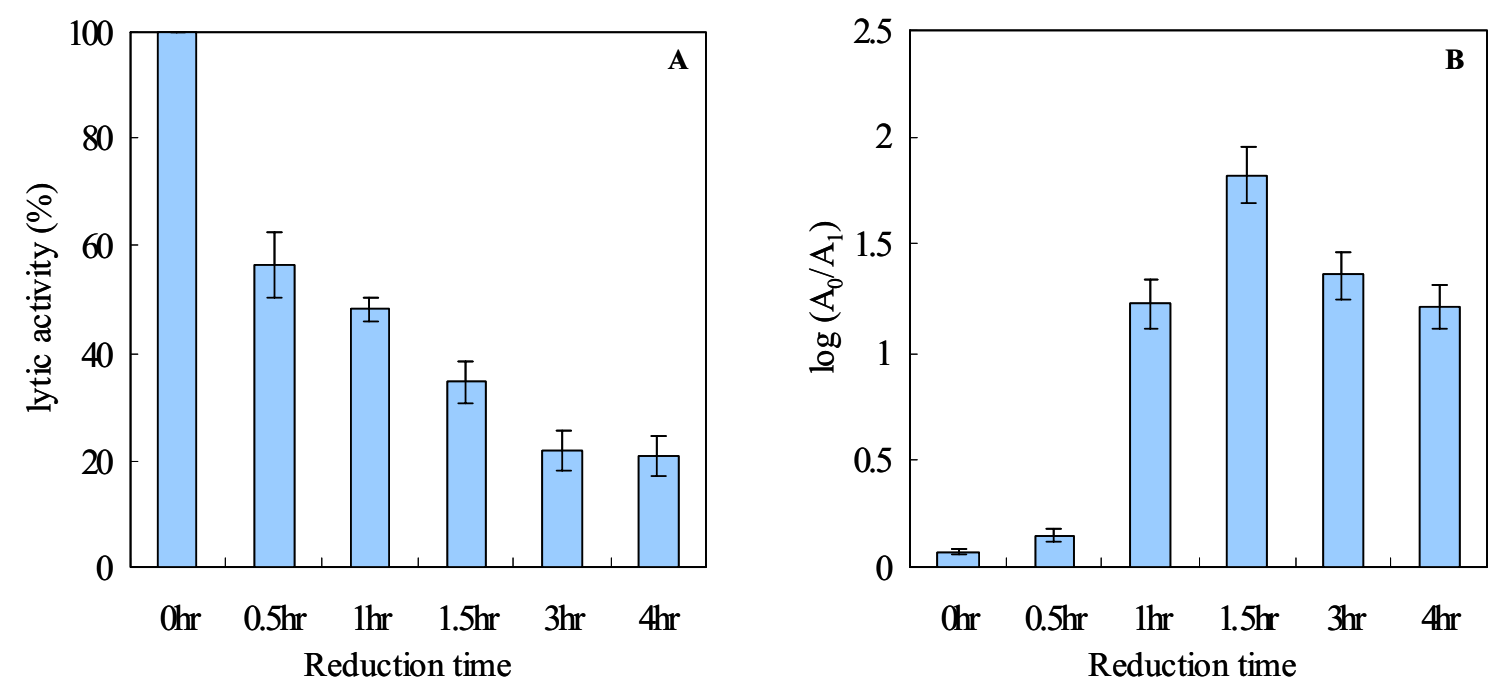

Figure 2. Effect of reduction time on (A) lytic activity against $M$. luteus and (B) antimicrobial activity against $S$. enteritidis IFO3313 of duck lysozyme. The experiment was done in triplicate. (A) Lysozyme 0.4 $\mu \mathrm{g} / \mathrm{ml}$; M. luteus $0.4 \mathrm{mg} / \mathrm{ml}$; temperature $37^{\circ} \mathrm{C}$; incubation time $2 \mathrm{~min}$. (B) Lysozyme $0.1 \mathrm{mg} / \mathrm{ml}$; S. enteritidis $10^{5} \mathrm{CFU} / \mathrm{ml}$; temperature $30^{\circ} \mathrm{C}$; incubation time $1 \mathrm{~h}$.

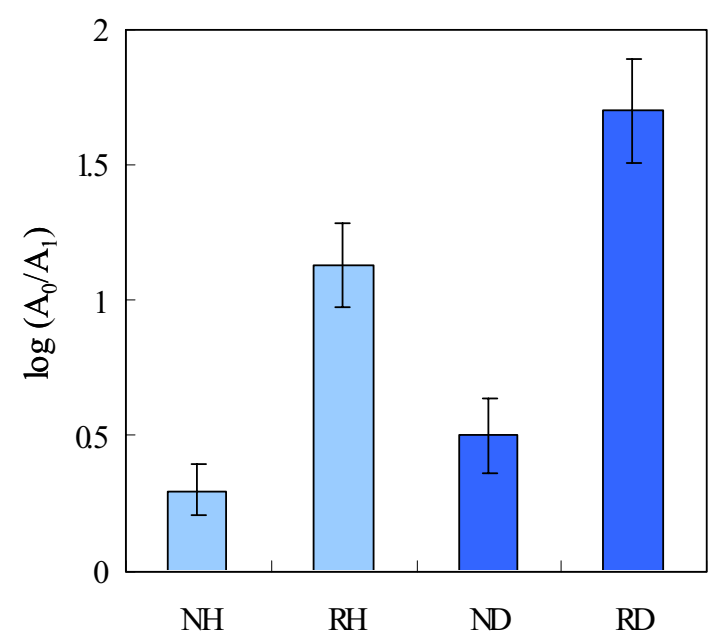

Figure 3. Antimicrobial activity of reduced / non-reduced lysozyme against S. enteritidis IFO3313. The experiment condition was reduced lysozyme $0.1 \mathrm{mg} / \mathrm{ml}$; S. enteritidis IFO3313 $10^{5} \mathrm{CFU} / \mathrm{ml}$; temperature $30{ }^{\circ} \mathrm{C}$; incubation time $1 \mathrm{~h}$. NH, native chicken lysozyme; $\mathrm{RH}$, reduced chicken lysozyme; ND, native duck lysozyme; RD, reduced duck lysozyme. 


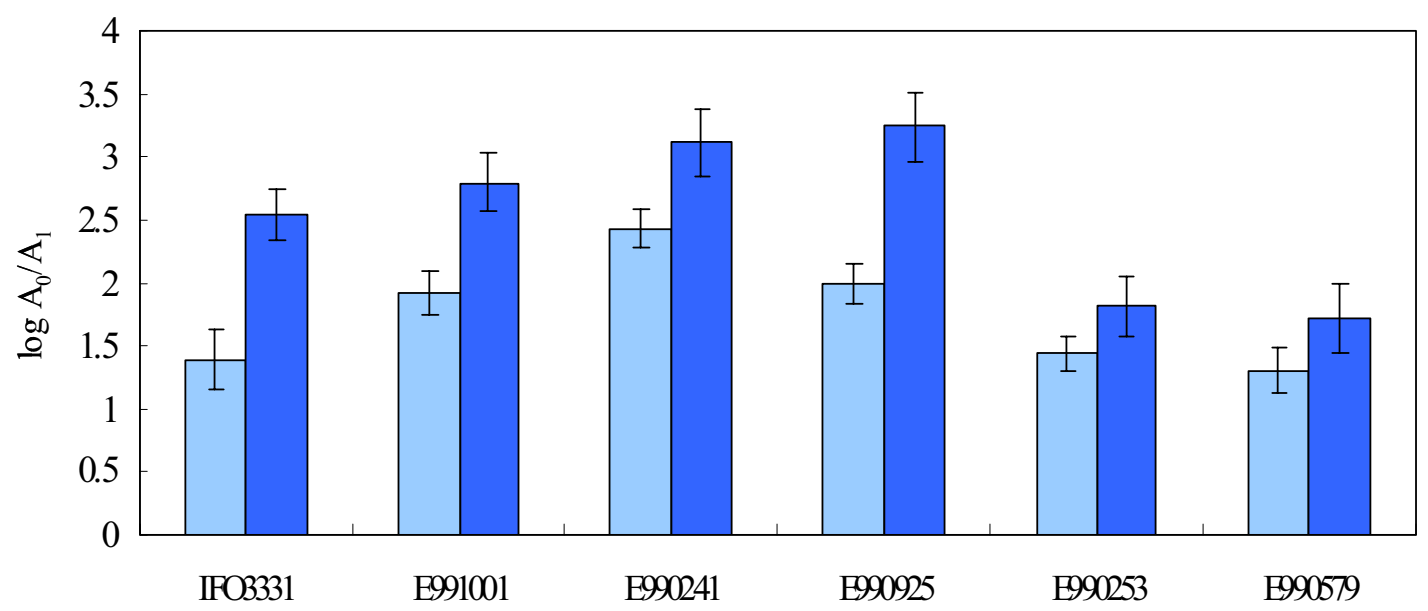

Figure 4. Antimicrobial activity of reduced lysozyme against several $S$. enteritidis contaminated in food. The antimicrobial activity was measured at reduced lysozyme concentration of $0.1 \mathrm{mg} / \mathrm{ml} ; S$.

enteritidis $10^{5} \mathrm{CFU} / \mathrm{ml}$; temperature $30^{\circ} \mathrm{C}$; incubation time $1 \mathrm{~h}$. Reduced chicken lysozyme ( $\square$ ); Reduced duck lysozyme ( $\square$ )

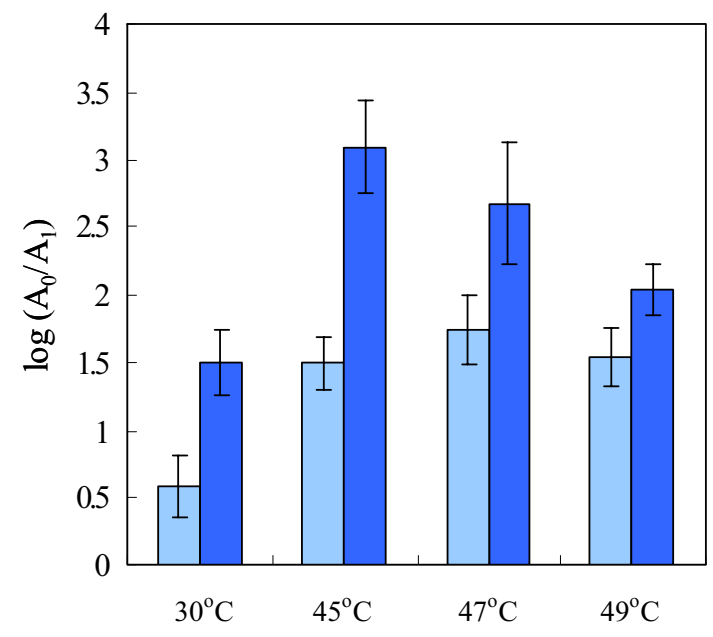

Figure 5. The effect of incubation temperature on antimicrobial activity of reduced lysozyme. The antimicrobial activity was measure at reduced lysozyme concentration of $0.1 \mathrm{mg} / \mathrm{ml} ; S$. enteritidis IFO $331310^{5} \mathrm{CFU} / \mathrm{ml}$; incubation time $1 \mathrm{~h}$. Reduced chicken lysozyme ( $\square$ ), Reduced duck lysozyme (口)

Since there are many factors that can affect antimicrobial activity, the effect of incubation temperature and food components were studied. Studying in incubation time, at 45 ${ }^{\circ} \mathrm{C}$ reduced dLz showed the highest antimicrobial activity (Fig. 5). Meanwhile, reduced cLz was proposed the highest activity when incubated at $47^{\circ} \mathrm{C}$. It was assumed that the rising of incubation temperature induced the bacteria physiology to be less active and affected bacteria membrane to be more fluid, enhancing the diffusion of reduced Lz (Russell, 2002). Moreover, hydrophobic interaction is a temperature dependence reaction. Therefore, reduced Lz may penetrate into bacteria membrane easier at the high incubation temperature. Thus, $45-47{ }^{\circ} \mathrm{C}$ was appropriate incubation temperature for reduced $\mathrm{Lz}$ to be used as antimicrobial agent. 

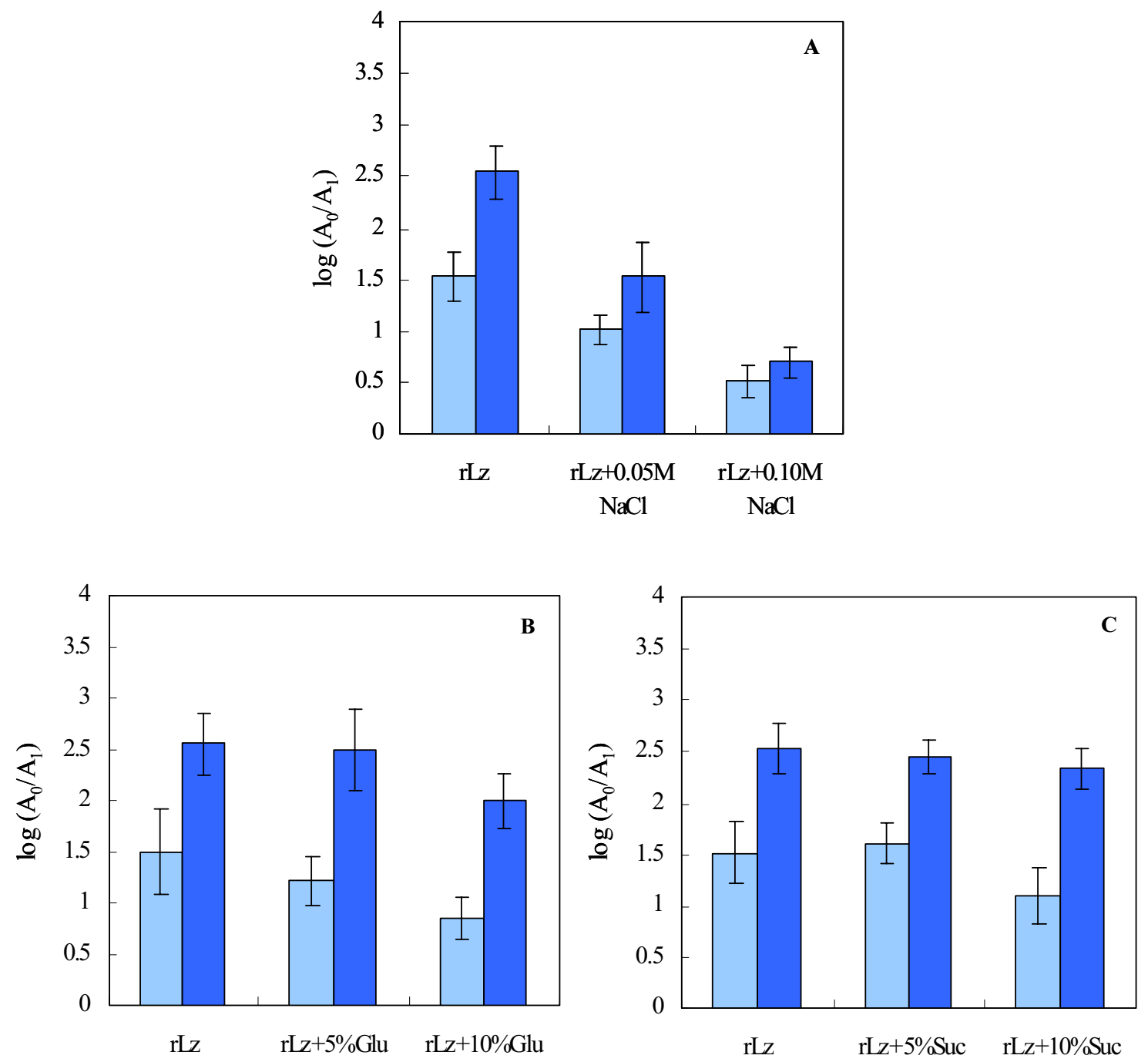

Figure 6. The effect of $\mathrm{NaCl}(\mathrm{A})$, glucose (B) and sucrose (C) on antimicrobial activity of reduced lysozyme. The measurement was performed at reduced lysozyme $0.1 \mathrm{mg} / \mathrm{ml} ;$ S. enteritidis IFO3313 $10^{5}$ $\mathrm{CFU} / \mathrm{ml}$; temperature $30^{\circ} \mathrm{C}$; incubation time $1 \mathrm{~h}$. rLz, reduced lysozyme; chicken lysozyme $(\square)$; duck lysozyme (口)

Salt or $\mathrm{NaCl}$ and sugar are widely used in the food industry as preservative agents, to impact sensory characteristics and to satisfy the human dairy requirement. According to the result of the effect of $\mathrm{NaCl}$, it showed that addition of $0.05-0.1 \mathrm{M} \mathrm{NaCl}$ decreased the activity of reduced Lz to the growth of $S$. enteritidis IFO3313 (Fig. 6A). The bactericidal effect of nisin against Listeria monocytogenes is the highest at low (near $0 \%$ ) or high $\mathrm{NaCl}$ concentration (near 6\%), while between 2 and $4 \% \mathrm{NaCl}$, the activity of nisin is low (Bouttefroy et al., 2000). The bactericidal activity of heat-treated $\mathrm{Lz}$ at $80{ }^{\circ} \mathrm{C}$ for $20 \mathrm{~min}$ at $\mathrm{pH}$ 6.0, termed HL80/6, against both E. coli and S. aureus is abolished by $0.1 \%$ and $1 \% \mathrm{NaCl}$ (Ibrahim et al., 1996). The difference in the effect of $\mathrm{NaCl}$ may be caused by the differences of antimicrobial agents and types of bacteria. The decrease in antimicrobial activity of reduced Lz may be due to the effect of monovalent cations which bind to the negatively charge head groups of the phospholipids in the cytoplasmic membrane and negative-charge of outer membrane as previously reported for divalent cations binding with cell membrane of 
gram-positive bacteria (Abee, 1995). This interaction may prevent the attachment of reduced $\mathrm{Lz}$ to bacteria cell. Moreover, $\mathrm{Na}^{+}$ions may have stimulated the biological process at the membrane by increasing the rate of membrane synthesis to repair the damage caused by reduced Lz (Ibrahim et al., 1996).

At the concentration of 5 and $10 \%$ glucose and sucrose slightly decreased antimicrobial activity of reduced Lz (Fig.6B and C). In addition, sucrose was demonstrated an ability of decrease the effect of HL80/6 to E.coli when the concentration of sucrose reached to $1.5 \%$, as reported in the previous study (Ibrahim et al., 1996). To be used as the foundational nutrition in bacteria growth, may explain the less effect of glucose and sucrose. However, small decrease in antimicrobial activity could be detected. The result may be from the increase in viscosity of the solution that influence to the attraction of reduced Lz and bacteria membrane.

Glycine and D-alanine are known as the essential components of bacteria cell that result in easier accessible approach into cells, making them to be interested as carrier molecules (Mishra et al., 2005). The result showed that glycine alone and its combination with reduced Lz possessed no effect on S. enteritidis (Fig. 7A). The effect of glycine up to $0.4 \%$ was not sufficient on the viability of either $S$. aureaus or E. coli, was reported (Ibrahim et al., 1996). However, the effect of combination between HL80/6 and glycine possessed the synergistic effect on both bacteria. This combination was sufficient in low-salt condition.

The addition of BSA affected the decrease in antimicrobial activity of reduced Lz as shown in Fig. 7B. As the incubation $\mathrm{pH}$ is 7.2 , BSA $(\mathrm{pI}=4.6)$ contains a negative charge that can bind to positive charge of $\mathrm{Lz}(\mathrm{pI}=10.7)$. This electrostatic interaction may prevent reduced $\mathrm{Lz}$ to bind to bacteria membrane with negative charge, resulting in the reduction of antimicrobial sufficiency of reduced Lz. Furthermore BSA is the good source of nutrition that bacteria can use for recovery during the incubation time.

According to the experiment, polyphosphate alone possessed a small effect on $S$. enteritidis (Fig. 8A). Meanwhile, the combination with polyphosphate improved the antimicrobial activity of reduced Lz. Phosphate is known as chelating compound, widely used as food additive in meat product and processing. The chelation of structurally essential metal ions, $\mathrm{Ca}^{2+}$ and $\mathrm{Mg}^{2+}$, in the cell walls, chelation of enzyme synthesis and inhibition of enzyme activity and changes in the water activity of the media increase the antimicrobial activity via improving the penetration property of antimicrobial compounds (Boland et al., 2003; Cutter et al., 1995; Vareltzis et al., 1997). Phosphate forms a metal-chelate ring by oxygen atoms founding the polyphosphate structure and metal ions. Thus, the disruption of polyphosphate to bacteria cell can increase the activity of reduced Lz against $S$. enteritidis. 

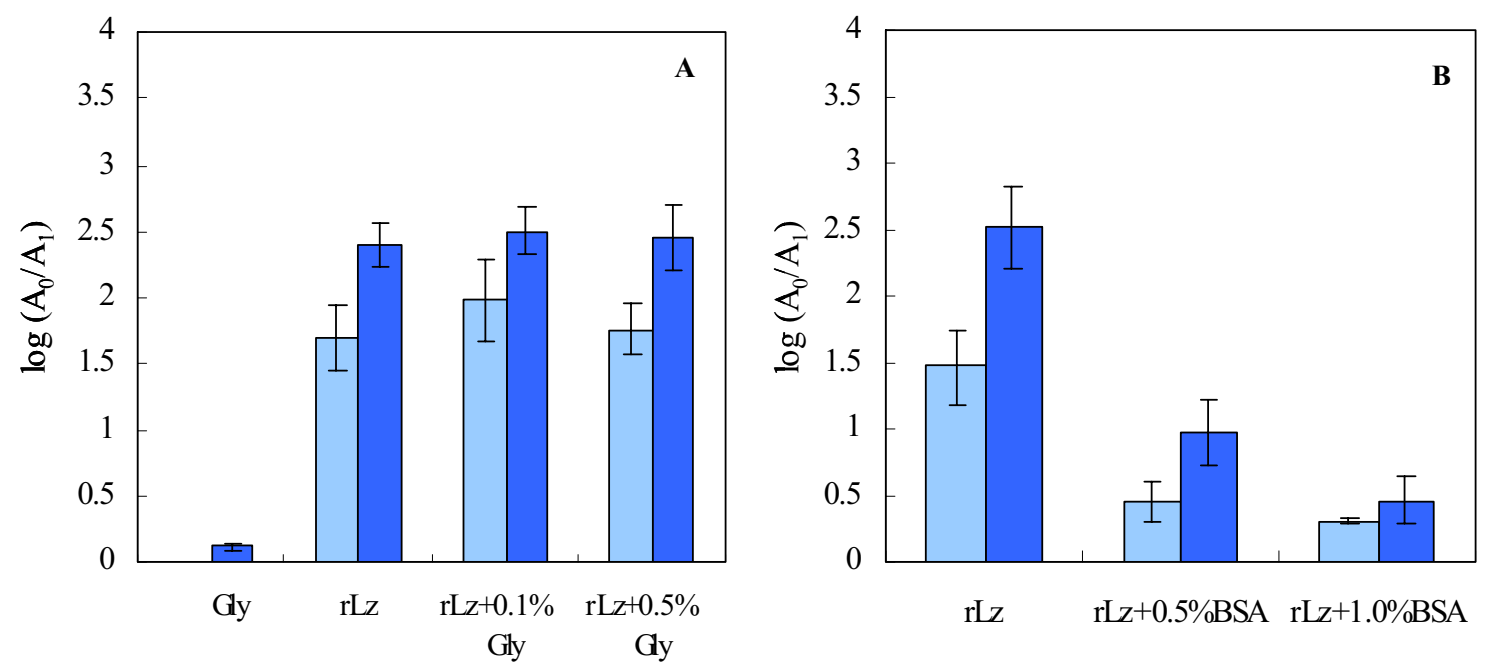

Figure 7. The antimicrobial effect of reduced lysozyme in the presence of glycine (A) and BSA (B). Reduced lysozyme $0.1 \mathrm{mg} / \mathrm{ml} ; S$. enteritidis IFO3313 $10^{5} \mathrm{CFU} / \mathrm{ml}$; temperature $30{ }^{\circ} \mathrm{C}$; incubation time 1 h. rLz, reduced lysozyme; chicken lysozyme $(\square)$; duck lysozyme $(\square)$
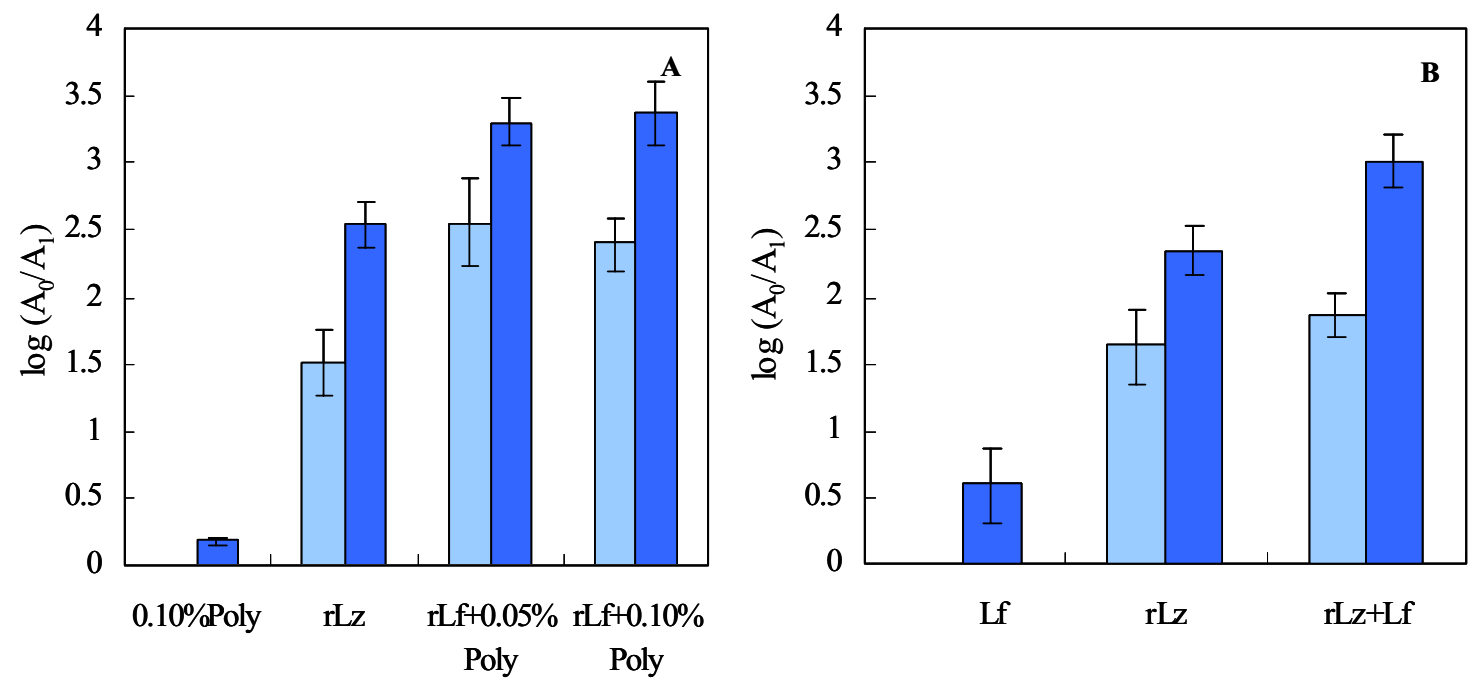

Figure 8. The effect of reduced lysozyme in the present of polyphosphate (A) and lactoferrin (B) on antimicrobial activity. Reduced lysozyme $0.1 \mathrm{mg} / \mathrm{ml} ; S$. enteritidis IFO3313 $10^{5} \mathrm{CFU} / \mathrm{ml}$; temperature $30{ }^{\circ} \mathrm{C}$; incubation time $1 \mathrm{~h}$. rLz, reduced lysozyme; chicken lysozyme ( $\square$ ); duck lysozyme $(\square)$

Lactoferrin, a glycoprotein, is found in milk and other exocrine secretions. It possesses an iron binding activity that can disrupt the structure of bacteria membrane. Not only that, the ability to release LPS from the outer membrane of gram-negative bacteria was reported recently (Ellison et al., 1991). The LPS-binding site is located on its N-terminal. Lactoferrin showed the synergistic effect in antimicrobial activity against $V$. cholera, E. coli, $S$. typhimurium and S. enteritidis when combined with native Lz, as reported (Elass-Rochard et al., 1995). It also showed the synergistic, when used connately with reduced Lz as showed in this study (Fig. 8B). 
As observed, the antimicrobial activity of $\mathrm{dLz}$ in native and reduced form, in all conditions of experiment, showed higher activity against $S$. enteritidis than cLz. It may be due to the differences of amino acid composition between these two Lzs. Compared with cLz, the contents of arginine, valine and tyrosine residue dLz were higher by a few residues, while those of aspartic acid, alanine and phenylalanine residues were lower by two, one and two residues, respectively (Kondo, 1982). The difference of arginine content in both Lz was also presented in other report. They showed that in dLz contains 13-15 arginine residues, while only 11 residues consist in cLz (Prager et al., 1971; Hermann et al., 1973; Kondo et al., 1982). Arginine plays an important role in the antimicrobial agent. The cationic charges of arginine provide an effective means of attracting with negative charged surfaces such as LPS, teichoic acid, or phosphatidyl glycerol phospholipids head group. Moreover, arginine can form a complex with tryptophans via cation- $\pi$ interaction which is favourable to penetrate into a lipid bilayer (Jing et al., 2003). The difference in arginine content may be responsible for high antimicrobial activity of $\mathrm{dLz}$.

\section{Conclusion}

The high antimicrobial activity of reduced Lz against $S$. enteritidis was reported in this study. It is supposed that reduced dLz could be the alternative antimicrobial agent for food industry to supply the customers who are concerned about natural foods, as it proposed higher activity than reduced cLz. Also this study, investigated that food components of ingredients such as $\mathrm{NaCl}$, sucrose, glucose and BSA have antagonism effects in antimicrobial activity of reduced Lz, while polyphosphate and lactoferrin promoted the efficiency of reduced lysozyme. In addition, Glycine did not have much effect. The effect of reduced duck lysozyme still needs more information about its activity in other bacteria and the effect of other food components.

\section{Reference}

Abee, T. Pore-forming bacteriocins of gram-positive bacteria and self protection mechanism of produces organisms. FEMS Microbiol. Lett. 1995, 129, 1-10

Boland, J. S.; Davidson, P. M.; Weiss, J. Enhanced inhibition of Escherichia coli 0157: H7 by Lysozyme and Chelators. J. Food Prot. 2003, 66(10), 1783-1789

Bouttefroy, A.; Mansour, M.; Linder, M.; Melliere, J. Inhibitory combinations of nisin, sodium chloride, and $\mathrm{pH}$ on Listeria monocytogenes ATCC 15313 in broth by an experimental design approach. Int. J. Food Microbiol. 2000, 54, 109-115

Branen, J. K.; Davidson, P. M. Enhancement of nisin, lysozyme and monolaurin antimicrobial activities by ethylenediamineteraacetic acid and lactoferrin. Int. J. Food Microbiol. 2004, 90, 63-74 
Cutter, C. N., Siragusa, G. R. Population reduction of gram negative pathogens following treatments with nisin and chelators under various conditions. J. Food Prot. 1995, 58, 977-983

Elass-Rochard, E.; Roseanu, A.; Legrand, D.; Trif, M.; Salmon, V.; Motas, C., Montreuil, J.; Spik, G. Lactoferrin-lipopolysaccharide interaction: involvement of the 28-34 loop region of human lactoferrin in the high affinity binding to Escherichia coli 055B5 lipopolysaccharide. Biochem. J. 1995, 312, 839-845

Ellison, R.T.; Giehl, T.J. Killing of gram-negative bacteria by lactoferrin and lysozyme. J. Clin. Invest. 1991, 88, 1080-1091

Facon, M. J.; Skura, B. Antibacterial activity of lactoferricin, lysozyme and EDTA against Salmonella enteritidis. Int. Dairy J. 1996, 6, 303-313

Gilquin, B.; Guilbert, C.; Perahia, D. Unfold of hen egg lysozyme by molecular dynamics simulations at 300K: insight into the role of the interdomain interface. Proteins, 2000, $41,58-74$

Hermann, J.; Jolles, J.; Jolles, P. The disulfide bridges of duck egg-white lysozyme II. Arch. Biochem. Biophys. 1973, 158, 355-358

Hunter, H. J.; Jing, W.; Shibli, D.; Trinh, T.; Park, I. Y.; Kim, S. C.; Vogel, H. J. The interactions of antimicrobial peptides derived from lysozyme with model membrane systems. Biochim. Biophys. Acta. 2005, 1668, 175-189

Ibrahim, H. R.; Kato, A. Design of amphipathic lysozyme using chemical and genetic modification to achieve optimal food functionality and diverse antimicrobial action In Food proteins structure and functionality; Schwenke, K. D.; Mothes, R., Eds; VCH Publishers, New York, 1992, 16-28

Ibrahim, H. R.; Higashiguchi, S.; Sugimoto, Y.; Aoki, T. Antimicrobial synergism of partially-denatured lysozyme with glycine: effect of sucrose and sodium chloride. Food Res. Int. 1997, 29(8), 771-777

Jing, W.; Demcoe, A. R.; Vogel, H. J. Conformation of a bactericidal domain of puroindoline : a structure and mechanism of action of a 13-residue antimicrobial peptide. J. Bacteriol. 2003, 185, 4938-4947

Kondo, K.; Fujio, H.; Amano, T. Chemical and immunological properties and amino acid sequences of three lysozyme from Peking-Duck egg white. J. Biochem. 1982, 91, 571-587

Laemmli, U. K. Cleavage of structural proteins during the assembly of the head of bacteriophage T4. Nature, 1970, 157, 105-132

Liu, S. T.; Sugimoto, T.; Azakami, H.; Kato, A. Lipophilization of lysozyme by short and middle chain fatty acid. J. Agric. Food Chem. 2000, 48, 265-269

Mine, Y.; Ma, F.; Lauriau, S. Antimicrobial peptides released by enzymatic hydrolysis of hen egg white lysozyme. J. Agric. Food Chem. 2004, 52, 1088-1094

Mishra, S.; Narain, U.; Mishra, R.; Misra, K. Design, development and synthesis of mixed bioconjugates of piperic acid-glycine, curcumin-glycine/alanine and curcumin-glycine- 
piperic acid and their antibacterial and antifungal properties. Bioorgan. Med. Chem. 2005, 13 (5), 1477-1486

Prager, E. M.; Wilson, A. C. Multiple lysozymes of duck egg white. J. Biol Chem. 1971, 246(2), 523-530

Russell, N. J. Bacterial membranes: the effects of chill storage and food processing. An overview. Int. J. Food Microbiol. 1997, 79, 27-34

Touch, V.; Hayakawa, S.; Saitoh, K. Relationships between conformational changes and antimicrobial activity of lysozyme upon reduction of its disulfide bonds. Food Chem. 2004, 84, 421-428

Vannini, L.; Lanciotti, R.; Baldi, D.; Guerzoni, M.E. Interactions between high pressure homogenization and antimicrobial activity of lysozyme and lactoperoxidase. Int. J. Food Microbiol. 2004, 94, 123-135

Vareltzis, K.; Soultos, N.; Koidis, P.; Ambrosiadis, Genigeorgis, C. Antimicrobial effects of sodium tripolyphosphate against bacteria attached to the surface of chicken carcasses. Lebensm.-Wiss. u. -Technol. 1997, 30, 665-669 